\title{
Convenient Conversion of Palm Fatty Acid Distillate to Biodiesel via Rice Husk Ash Catalyst
}

\author{
Zainab Ngaini $^{1}$ [D $\cdot$ Nurfarahen Jamil $^{1} \cdot$ Rafeah Wahi $^{1} \cdot$ Farra Diana Shahrom $^{1} \cdot$ Zainal Abiddin Ahmad $^{2} \cdot$ Saba Farooq $^{1}$
}

Received: 3 May 2021 / Accepted: 3 September 2021

() The Author(s), under exclusive licence to Springer Science+Business Media, LLC, part of Springer Nature 2021

\begin{abstract}
Silica-based heterogeneous catalyst derived from rice husk ash (RHA) was used for the transformation of palm fatty acid distillate (PFAD) into biodiesel. The production of the biodiesel from PFAD was conducted via esterification and transesterification employing Huskcatacid and Huskcatbase, respectively. The biodiesel was analyzed from different parameters, i.e., amount of catalyst, oil to methanol ratio, temperature, and reaction times. The outcomes depicted Huskcatacid was efficient for PFAD esterification to produce 91.6\% ester with $5 \mathrm{wt} \%$ catalysts and 5:1 (MeOH:PFAD), followed by the transesterification using $1 \mathrm{wt} \%$ Huskcatbase in 3:1 (MeOH:oil) to generate $99.73 \%$ biodiesel with a high percentage of methyl oleate (57.86\%) and methyl palmitate (34.43\%). Huskcatacid and Huskcatbase depicted a high surface area $\left(7.362 \mathrm{~m}^{2} / \mathrm{g}^{2}\right.$ and $\left.14.493 \mathrm{~m}^{2} / \mathrm{g}\right)$ and high porosity $\left(2.726 \times 10^{-3} \mathrm{~cm}^{3} / \mathrm{g}\right.$ and $\left.4.985 \times 10^{-3} \mathrm{~cm}^{3} / \mathrm{g}\right)$, respectively, that contributed to the efficient esterification and the easy separation of glycerol. The PFAD-derived biodiesel was tested on the Megatech®-Mark III engine and confirmed the proportional torque ( $\mathrm{r}$ ) increment with the loading of B100 biodiesel. Rice husk showed promising outcomes as solid-support heterogeneous catalysts and the production of value-added products to reduce the agricultural waste management issues.
\end{abstract}

Keywords Biomass $\cdot$ Heterogeneous $\cdot$ Esterification $\cdot$ Triacylglycerol $\cdot$ Saponification

\section{Introduction}

Catalyst plays a vital role in the transesterification reaction of free fatty acids (FFA) to form biodiesel. The synthesis of an ideal catalyst for biodiesel production has gained the attention of researchers in the recent decade. Sulfuric acid $\left(\mathrm{H}_{2} \mathrm{SO}_{4}\right)$ and hydrochloric acid $(\mathrm{HCl})$ are common acid catalysts used to speed up the transesterification process for the formation of biodiesel with higher yield [1-4]. Major issues of acid catalysts are the corrosive effect on the reactor and the high amount of alcohol required, which incur high production costs [5]. Homogeneous base catalyst such as sodium hydroxide $(\mathrm{NaOH})$ and potassium hydroxide $(\mathrm{KOH})$ exhibited faster and noncorrosive reactions during

Zainab Ngaini

nzainab@unimas.my

1 Faculty of Resource Science and Technology, Universiti Malaysia Sarawak, 94300 Kota Samarahan, Sarawak, Malaysia

2 Department of Petrochemical Engineering, Kuching Polytechnic, 93050 Kuching, Sarawak, Malaysia the production of biodiesel. However, homogeneous base catalyst suffers disadvantage due to saponification effect which reduces the yield of biodiesel $[5,6]$. Heterogeneous catalysts like tungstate [7], angel wing shell [8], silica nanoparticles [9], and titanium dioxide [10] were then explored as alternatives available to homogenous biodiesel catalysts. However, the drawbacks of these catalysts are costly materials, multistep synthesis, difficult processing, and low catalytic activity [11].

Heterogeneous base catalysts such as calcium oxide and silica have been reported to produce a higher yield of biodiesel compared to homogeneous base catalysts [5]. Nevertheless, the catalysts have difficulty diffusing into the product mixture to form oil, alcohol, and catalyst [12]. This limitation has led to the introduction of catalyst support for heterogeneous base catalysts to increase the reaction with triacylglycerol [13]. The catalyst support is a solid carrier impregnated with an active species [14]. For instance, $\mathrm{NaOH} / \mathrm{Al}_{2} \mathrm{O}_{3}, \mathrm{NaOH} / \mathrm{SiO}_{2}$, and $\mathrm{ZS} / \mathrm{Si}$ have been used as catalyst supports in the production of biodiesel [15-17].

The use of biomass-based catalysts from agricultural waste in biodiesel production has reduced the overall cost 